\title{
Um livro sob medida como instrumento do ensino de aritmética na escola primária
}

\section{Un libro a la medida como herramienta para la enseñanza de la aritmética en la escuela primaria}

\author{
Nara Vilma Lima Pinheiro*
}

ORCID iD 0000-0003-2868-4435

\begin{abstract}
Resumo
A pedagogia renovada, em tempos da Escola Nova, apontava a necessidade de se produzirem saberes sobre o sistema escolar, segundo uma lógica organizada por regras específicas do mundo científico, com o objetivo de tornar a escola mais eficiente. $\mathrm{Na}$ análise dos discursos da época, nota-se que o desejo de racionalização do ensino não deixou escapar sequer o livro escolar, o qual deveria ser elaborado sob medida, subordinado à ordem psicológica do sujeito que aprende. Considerando o contexto de racionalização do ensino, interessa discutir, neste texto, as modificações sistematizadas no livro de aritmética para a escola primária. De modo específico, trata-se de analisar o livro Nossa Aritmética, resultado de experiências científicas desenvolvidas em escolas primárias do Rio de Janeiro. O cruzamento das fontes evidencia uma maior preocupação com a eficiência e com o rendimento do aluno do que com a aprendizagem da matemática em si.
\end{abstract}

Palavras-chave: Aritmética. Livro didático. Ensino primário. História da Educação Matemática.

\section{Resumen}

La pedagogía renovada, en tiempos de la nueva escuela, apuntaba a la necesidad de producir conocimiento sobre el sistema escolar, de acuerdo con una lógica organizada por reglas específicas del mundo científico, con el objetivo de hacer la escuela más eficiente. El análisis de los discursos de la época revela que el deseo de racionalizar la enseñanza ni siquiera dejó escapar el libro escolar, que debería elaborarse a medida, subordinado al orden psicológico de la asignatura de aprendizaje. Considerando el contexto de racionalización de la enseñanza, es interesante discutir, en este texto, los cambios sistematizados en el libro de aritmética para la escuela primaria. Específicamente, se trata de analizar el libro Nossa Aritmética, resultado de experimentos científicos desarrollados en escuelas primarias de Río de Janeiro. El cruce de las fuentes muestra una mayor preocupación con la eficiencia y el rendimiento del estudiante, que con el aprendizaje de las matemáticas en sí.

Palabras clave: Aritmética. Libro de texto. Educación primaria. Historia de la educación matemática.

\section{Introdução}

No início do século XX, questões referentes à (re)organização escolar fizeram-se presentes nos discursos dos intitulados renovadores da educação, no âmbito do ideário reformista. Tais discursos defendiam um modelo de organização escolar que tinha certa

\footnotetext{
* Doutora em Ciências pela Universidade Federal de São Paulo (UNIFESP). Pós-doutoranda na Faculdade de Educação da USP (FEUSP), São Paulo, São Paulo, Brasil. E-mail: naravlp@yahoo.com.br.
} 
semelhança com o taylorismo e impunham "à escola a necessidade de fixação racional de metas e meios para a execução do trabalho docente" (CUNHA, 1993, p. 195).

No discurso de Lourenço Filho (1929, p. 298), sob a perspectiva da eficiência e do rendimento, a escola era vista "como a produção das modernas indústrias, que deve ser rápida, precisa, com perdas mínimas de energia e pessoal. É o espírito americano da eficiência e do 'standard'. É o taylorismo na escola".

Segundo esse pensamento, desejava-se uma escola sob medida, que levasse em consideração as necessidades individuais das crianças. Uma escola ajustada à criança, tal como o alfaiate ao produzir uma roupa, ou o sapateiro um sapato. Ambos ajustam a roupa e/ou o sapato às medidas de seu cliente, e, se ele é gordo ou pequeno, eles não lhe impõem uma peça muito estreita ou muito curta sob o pretexto de que a largura ou comprimento não correspondam ao seu tamanho. Ao contrário, a escola veste, calça e coloca todas as mentes da mesma maneira porque ela não tem, pelo espírito, o mesmo respeito que se tem pelo corpo (CLAPARÈDE, 1973).

Com a ideia de ajustar a escola às diferenças individuais, almejava-se uma nova organização escolar, de modo a acolher as experiências que vinham se desenvolvendo no âmbito da pedagogia científica. A nova organização, com chancela científica, não mais permitiria a composição das classes com base na idade de cada um, mas pautada numa seleção a partir de resultados de testes psicológicos. O processo de aprendizagem também não poderia mais seguir a ordem já consolidada, no âmbito escolar, de partir "do simples para o complexo; do que se sabe para o que se ignora; dos fatos para as causas; das coisas para os nomes; das ideias para as palavras; dos princípios para as regras" (CALKINS, 1950, p. 31).

$\mathrm{Na}$ esteira de cientificidade, as pesquisas, em grande escala, apresentaram uma ordem diferente para o processo de aprendizagem, uma ordem dependente do sujeito que aprende. Nesse caso, a aprendizagem processar-se-ia do fácil para o difícil, e o ensino deveria ser estruturado de modo a fornecer aos alunos os saberes que ele pode aprender, ao invés daqueles que ele deve aprender (VALENTE, 2015). Assim, a ordem lógica de estruturação dos conteúdos precisou ser alterada para uma ordem psicológica, dada pelos "resultados das testagens em grande escala, com alunos e as lides com conteúdos que podem aprender" (PINHEIRO; VALENTE, 2017, p. 86).

Essas testagens foram elaboradas por experts em educação, por sujeitos selecionados "pelo fato de conhecerem perfeitamente o ofício docente e nele se destacarem" por seus conhecimentos teóricos e práticos (HOFSTETTER; SCHNEWUWLY; FREYMOND, 2017). 
A esses experts foi dada a tarefa ${ }^{1}$ de produzirem saberes sobre o sistema escolar, segundo uma lógica organizada por regras específicas do mundo científico, de modo a fornecerem respostas práticas ao problema do rendimento e da eficiência do ensino primário. Tratava-se de fornecer aos reformadores educacionais ferramentas de decisão que justificariam uma reorganização do aparelho escolar.

Os saberes produzidos pelos experts, ao longo do tempo, foram perdendo sua subjetividade, passando a ser aceitos de modo mais genérico, tornando-se consensos pedagógicos, passíveis de sistematização e objetivação, visando à sua utilização em diversos contextos. Essa sistematização pode ser dada a ler em livros escolares, "depositários de conteúdos educativos", cujo papel é "transmitir às jovens gerações os saberes, as habilidades (mesmo o 'saber-ser') os quais, em dada área e a um dado momento, são julgados indispensáveis à sociedade para perpetuar-se" (CHOPPIN, 2002, p. 14, grifo do autor).

Tal foi o caso de Alfredina de Paiva $S_{0 u z a}{ }^{2}$, professora de Cálculo e Prática de Ensino, da Escola de Professores do Instituto de Educação do Rio de Janeiro, que, a partir do aval de Anísio Teixeira, diretor de Instrução Pública, desenvolveu experiências científicas em escolas primárias da então capital do país, com o objetivo de ajustar o ensino de cálculo aritmético às diferenças individuais. Suas experiências, vivências de sala de aula e atuação profissional resultaram na elaboração de uma aritmética sob medida, com o fim prático de execução rápida e precisa das quatro operações e aplicação às situações reais da vida cotidiana, uma aritmética ajustada à maturidade infantil, tendo em conta o sujeito que aprende (PINHEIRO, 2017). A sistematização dessa aritmética é dada a ler na obra Nossa Aritmética, publicada em 1937, de sua autoria.

Neste artigo, considerando o contexto de racionalização do ensino e, em específico, da elaboração de uma aritmética sob medida, a perspectiva de análise permite examinar as modificações e sistematizações presentes em Nossa Aritmética.

\section{$2 \mathrm{O}$ livro didático como instrumento do ensino}

O desejo de racionalização do ensino não deixou escapar nem o livro escolar. Em discurso pronunciado no encerramento da Semana do Livro, em 1933, no Instituto de Educação de São Paulo, Fernando de Azevedo estabelecia a diferença entre o livro utilizado

1 Entendemos por tarefa uma ação que envolve "a modificação pelo indivíduo de seu ambiente (no sentido amplo de ambiente material ou conceitual)", e que implica uma finalidade (REY, 2006, apud MORAIS; VALENTE, 2020, p 7-8).

${ }^{2}$ Sobre a trajetória acadêmica de Alfredina, ver uma discussão mais aprofundada em Almeida (2013). 
na escola tradicional e o livro na Escola Nova. Em sua nova função, o livro deixava de ser visto como "regulador das atividades, como imposição ao natural desenvolvimento do espírito infantil", passando a ser considerado como "instrumento de trabalho e auxiliares, aos quais têm de recorrer para obter dados e informações, esclarecer dúvidas, recolher material de estudos e de reflexão ou por simples prazer" (AZEVEDO, 1953, p. 191-192).

Materializar a nova função do livro escolar parece não ter sido tarefa fácil. Quatro anos mais tarde, Leontina Silva Bush, professora da Escola Normal Padre Anchieta (São Paulo), em artigo publicado na revista Idort (Instituto de Organização Racional do Trabalho), retomava o discurso de Azevedo para tratar da Racionalização no Preparo dos Livros Didáticos. Ela reclamava do empirismo pedagógico, que acorrentava o professorado e os autores de livros didáticos da escola primária. Compreendia que, qualquer que fosse o ramo do conhecimento, havia sempre uma fase preliminar de empiria, de tateamento, para, em seguida, vir uma fase "mais raciocinada, sistematizada e correlacionada com princípios das ciências" (BUSCH, 1937, p. 36).

Entretanto, no âmbito escolar, havia certa "resistência para aceitar e aplicar princípios de orientação científica" que já vinham sendo experimentados há muito tempo, prejudicando a “evolução das técnicas racionais, como no caso do ensino, em que novos métodos estão a oferecer aos mestres recursos garantidores de maior rendimento qualitativo e quantitativo de seu trabalho" (BUSCH, 1937, p. 36). Seria a resistência fruto "do espírito conservador" de professores e autores que se fechavam “à renovação pedagógica por temer-lhe os extremismos"? Ou seria a resistência fruto de uma ausência de cultura pedagógica moderna que lhes impedia de obter "o máximo de proveito da ciência da educação na obra de racionalização das técnicas do ensino" (BUSCH, 1937, p. 36)?

Sem alongar-se sobre essas questões, Leontina dava indicativos das características necessárias para que um livro didático de leitura fosse elaborado de modo a seguir os princípios científicos psicológicos sobre o desenvolvimento infantil. Inicialmente, o livro deveria modificar a sua forma, considerando "o meio social a que se destinava a fim de fazer dele um instrumento agradável de ajustamento dos aprendizes ao estado de civilização do meio" (BUSCH, 1937, p. 37). Para tanto, o autor deveria conhecer a psicologia infantil e colocar-se "em situação de uma criança para produzir o que pode interessar à vida dos escolares nas etapas sucessivas de seu conhecimento" (BUSCH, 1937, p. 37).

No caso dos conteúdos, o primeiro ponto a considerar-se seriam as ilustrações, pois tinham por função despertar nos alunos "certas condições internas, que tendem a iniciar, a dirigir e a manter as atividades e os esforços deles no aprendizado de cada lição" (BUSCH, 
1937, p. 58). No entanto, qualquer ilustração no alto da página, por exemplo um animal, não constituiria uma lição interessante, a não ser que o animal estivesse em situação de brincadeira, por exemplo, "cãezinhos em atitude de brinquedo, gatos brincando com bolinha, ou outras cenas de que participem animais domésticos podem predispor facilmente os aprendizes à atividade de indagação e curiosidade" (BUSCH, 1937, p. 58).

$\mathrm{Na}$ perspectiva da autora, as ilustrações deveriam propiciar um grau de realismo das ações infantis divertidas, de brincadeiras do cotidiano infantil. Também o vocabulário e a linguagem deveriam atender à demanda infantil. O livro deveria ser escrito em "estilo gracioso, assumindo tom de expressão infantil”, com palavras que tivessem significado para os alunos, que refletissem a atividade da vida familiar ou do grupo social a que pertenciam (BUSCH, 1937, p. 60). O autor do livro deveria considerar, ainda, várias recapitulações, pois as "experiências psicológicas apontaram que o aprendizado se processa pela repetição agradável do que se objetiva fixar, guardando-se, entre a atividade de aprender uma noção e suas repetições sucessivas, intervalos de tempo destes ótimos" (BUSCH, 1937, p. 60).

Nesse ponto, é importante frisar que as experiências científicas deram papel de destaque para a memória na educação. Vista em tempos outros como a vilã do ensino, a memória passou a ser considerada como o método mais natural de aprender-se a partir da atenção e da repetição (BINET, 1909).

As mudanças sugeridas por Leontina não seriam somente internas. Ao contrário, os elementos mais importantes encontravam-se na capa do livro: no título e na ilustração, pois seriam eles os responsáveis por despertar o interesse da criança. Junto ao título, a ilustração da capa deveria "focalizar cena de sugestão da vida da criança, que poderão ser o motivo de uma das lições" (BUSCH, 1937, p. 61).

Dadas as orientações de como deveria ser elaborado um livro didático, Leontina considerava essa tarefa de natureza difícil quando não havia no mercado editorial critérios e diretrizes definidas para orientar os autores. No entanto, isso parecia estar com dias contados, ao menos em São Paulo, onde a Diretoria de Ensino organizou uma ficha para orientar a apreciação dos livros escolares utilizados em escolas e daqueles submetidos à aprovação oficial. Essa medida visava "fazer passar por um crivo de atualização pedagógica todas as produções que foram aprovadas nos anos anteriores, porque precisam evidentemente servir aos objetivos do ensino de então, e agora necessitam possivelmente de ser refundidas ou melhoradas" (BUSCH, 1937, p. 36). Somava-se a isso, a estratégia da Diretoria de Ensino em aumentar o número de professores convocados a examinar e dar parecer aos novos livros escolares, contribuindo para uma "infiltração da cultura renovada" (BUSCH, 1937, p. 36). 
Na tentativa de uniformização do ensino no âmbito brasileiro, criou-se, em 1938, a Comissão Nacional do Livro Didático (CNLD), com a função de examinar e autorizar o uso dos livros escolares nas escolas de todo o país. Segundo Mont'Alegre (1941, p. 139), os livros escolares brasileiros deveriam seguir o modelo adotado na Itália ou no México, adotando "apresentação discreta, orientados, porém dentro dos princípios mais rigorosos da pedagogia; pode-se dizer que são feitos sob medida", subordinados à ordem psicológica do sujeito que aprende.

Tal assertiva já vinha desenvolvendo-se no Rio de Janeiro por Alfredina de Paiva Souza. Em ano anterior à CNLD, Alfredina havia publicado Nossa Aritmética, um livro elaborado sob medida, a partir de resultados de pesquisas científicas desenvolvidas no âmbito do Instituto de Educação do Rio de Janeiro.

Nossa Aritmética, editado pela Livraria do Globo, foi bem avaliado por Alceu da Silveira em artigo publicado na Revista Brasileira de Pedagogia. Nesse artigo, Alfredina passou a ser reconhecida como uma expert brasileira em pedagogia científica, sobretudo no campo da matemática, ao ser considerada por Silveira (1937, p. 522) como "uma das inteligências mais possuídas do verdadeiro espírito da pedagogia científica". Fruto de experiências científicas e de pesquisas sobre os livros de matemática editados no Brasil, Nossa Aritmética inaugurava "novos rumos para os livros didáticos" de matemática (SILVEIRA, 1937, p. 522).

Para o autor supracitado, o livro didático deveria romper com o empirismo, com as opiniões sem fundamentação científica e, principalmente, com o improviso. Nos seus próprios dizeres: "não adianta improvisar tipo de somas, subtrações, multiplicações e divisões a fazer, quando Nossa Aritmética dosa estes cálculos com inteira precisão científica" (SILVEIRA, 1937, p. 522).

Best seller da aritmética, o livro de Antônio Trajano foi considerado ultrapassado, "abrindo e fechando com diálogos capítulos insípidos" de sua obra (SILVEIRA, 1937, p. 523). Em suas críticas, Silveira (1937, p. 523) ia além de tecer críticas a obras já consagradas, alertava que não bastaria fazer leituras de psicólogos renomados como Lennes ou Thorndike e depois espalhar "no texto de manuais antigos de matemática jogos, adivinhações, versos e desafios".

Em Nossa Aritmética, a pedagogia científica materializava-se, "deduzindo de pesquisas brasileiras atividades que não estão ajuntadas aos números, mas que com eles formam um todo orgânico, espontâneo e indivisível” (SILVEIRA, 1937, p. 522). Tomando, por exemplo, a tabuada - aprendida pela repetição mecânica de noções não assimiladas - as 
experiências de Alfredina alteravam a ordem lógica das combinações, "facilitando o surgimento de repetições oportunas e criando exercícios de velocidade, muito de acordo com a psicologia" (SILVEIRA, 1937, p. 522).

Não se tratava de didatizar a tabuada por uma nova metodologia. Os resultados coletados por Alfredina e sistematizados em Nossa Aritmética vinham comprovar que a tabuada não era um conteúdo invariante, pois ela se alterou e se modificou com a pedagogia científica, o que corrobora a ideia defendida por Chervel (1990) de que a pedagogia não é um lubrificante, mas o mecanismo que modifica a natureza e a forma dos próprios saberes de referência, a fim de torná-los ensináveis, trabalho que implica uma organização específica da aprendizagem escolar.

Os elogios à Nossa Aritmética ultrapassam os limites da cidade do Rio de Janeiro, na resenha de Abel Fagundes, publicada na Revista do Ensino de Minas Gerais, em 1938. Para respaldar seus elogios, Fagundes (1938, p. 205) ampara-se em autores renomados, os quais, em seus dizeres, "se manifestaram, com rasgados encômios, os nossos maiores entendidos em matemática e metodologia, bastando mencionar Backheuser e Baltazar da Silveira”. Apesar de tecer algumas poucas críticas à autora, em razão de o livro trazer ao final um questionário destinado a saber a opinião do professor, Fagundes (1938) indicava a adoção de Nossa Aritmética nas escolas primárias mineiras.

É importante, nesta altura, analisar com detalhe a obra Nossa Aritmética com a finalidade de melhor compreender as modificações que a racionalização do ensino sedimentou no livro didático de matemática destinado à escola primária.

\section{A aprendizagem da aritmética no livro sob medida}

Alguns aspectos na capa de Nossa Aritmética chamam-nos atenção. A começar pelo título, cujos caracteres utilizados assemelham-se à escrita manual, de próprio punho, sem se prender à estrutura tipográfica da época. Ao optar por inserir o pronome possessivo Nossa, a autora dá a ideia de que a aritmética é algo que nos pertence e que devemos nos apropriar dela. Ao mesmo tempo, rompe com os tradicionais títulos dos livros de aritmética, tais como: Tratado de Aritmética, Compêndio de Aritmética, Aritmética Prática, dentre tantos outros.

Um segundo aspecto diferenciado, ainda na capa, refere-se à ilustração colorida de crianças brincando, conforme Figura 1. Trata-se de uma cena que relaciona situações da vida infantil com aquelas da vida adulta, ao trazer crianças em suas experiências numéricas (a compra de ingredientes, as medidas, o relógio, o uso da régua, a contagem, as maçãs divididas 
em partes, dentre outras possibilidades). Posteriormente, as atividades representadas na ilustração da capa seriam motivos das lições. Esses aspectos funcionavam como ferramenta para despertar o interesse e prender a atenção da criança para aquilo que seria ensinado.

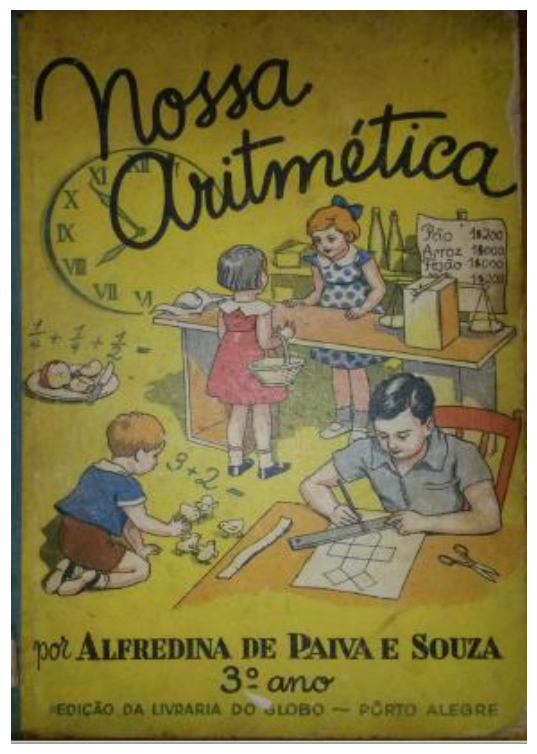

Figura 1 - Capa de Nossa Aritmética Fonte: SOUZA (1937)

Ao folhearmos o livro, deparamo-nos com uma maneira diferente de escrita. Observamos a autora dialogando diretamente com as crianças, convidando-as a participarem da construção do livro, tendo em vista que as histórias, apresentadas a partir de ilustrações coloridas, deveriam ser completadas no decorrer da aprendizagem. Segundo Fagundes (1938, p. 209), em proposta inicial à Editora, Alfredina desejou que as ilustrações não fossem coloridas, colorir ficaria a cargo das crianças que, assim, vivenciariam a "sensação de serem coautoras do livro, praticariam exercício útil e se interessariam mais por ele". A ideia de Alfredina era que as crianças vissem o livro de aritmética como um de seus brinquedos e interagissem com ele por meio da escrita de coisas inventadas e de ações como pintar, recortar e colar. Tratava-se de brincar-fazer-aprender.

Longe está o tempo de diálogo na forma catequética, de pergunta e resposta dos antigos livros escolares. O diálogo proposto por Alfredina parecia querer adentrar a imaginação das crianças, criando situações que pretendiam um brincar estudando. Convidava as crianças para serem suas sócias na finalização da escrita do livro. Para tanto, elas deveriam completar as histórias, escrevendo nos espaços pontilhados. Ao finalizar "a escrita do livro" a criança poderia completar a ficha de "sócio colaborador" e avisar Alfredina, por meio de correspondência, que esperaria "ansiosa" para que o trabalho ficasse pronto (SOUZA, 1937, p. 10). 
É nessa dinâmica do brincar-fazendo que se inicia o livro, com a ilustração de uma atividade cotidiana como ponto de partida para a história que seria narrada, em uma linguagem acessível às crianças. Tal como previa o Programa de Ensino (DEPARTAMENTO DE EDUCAÇÃO DO DISTRITO FEDERAL, 1934, p. 20), o qual orientava que o estudo da matemática tomasse como ponto de partida "situações reais da vida da criança que a levem, naturalmente, a precisar da matemática, que, portanto, não se estudará desligada da vida prática, para lhe ser depois aplicada”. Nesse caso, a autora se valeu da ocupação de carteiro, tendo em vista que seria ele a entregar a carta escrita pelas crianças (conforme Figura 2), para retomar um conteúdo já aprendido em anos anteriores: a numeração.

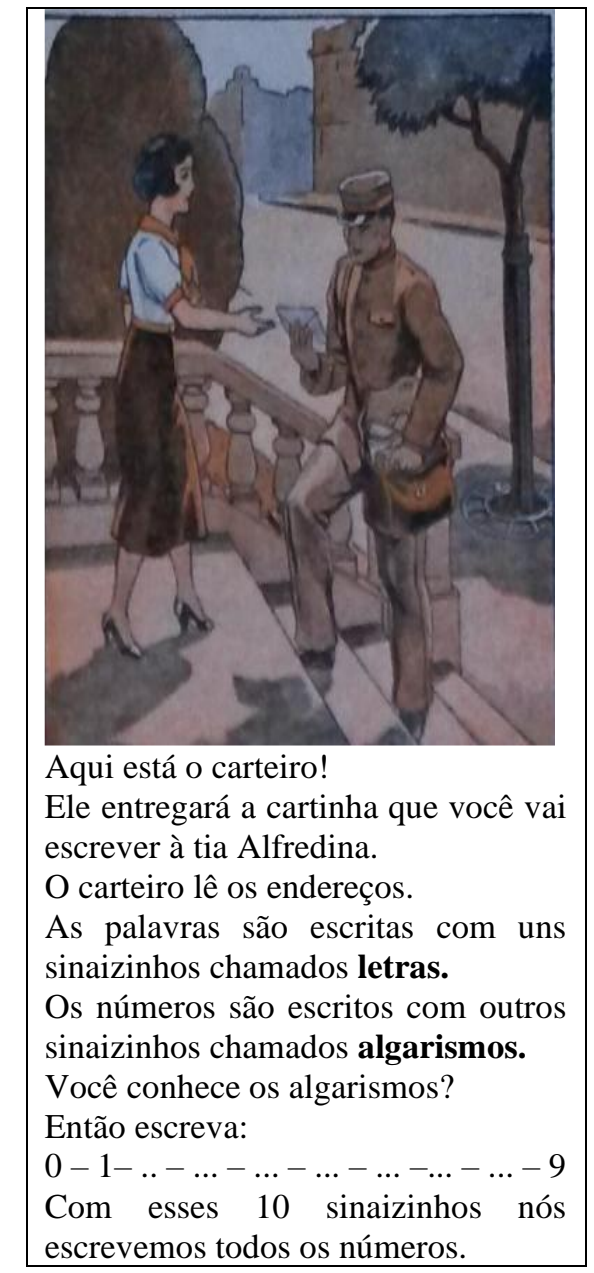

Figura 2 - Ilustração inicial do livro Fonte: SOUZA (1937, p. 8)

A partir dessa ilustração, situações vão aparecendo para a retomada de certos conteúdos aritméticos já aprendidos anteriormente. Primeiro, a sequência numérica e, gradualmente, os números simples (unidades), os números compostos (dezenas), os números pares e ímpares, a divisibilidade por dois, dentre outros. O livro foi organizando-se de modo que cada conteúdo, cada atividade, se relacionassem entre si. 
O título de cada capítulo incitava a criança a entrar, com entusiasmo, na aprendizagem que lhe era proposta. Não se tratava mais de nomear cada capítulo tendo em vista a linguagem e a ordem de conteúdos matemáticos. Um mesmo conteúdo foi tratado de diferentes maneiras, por meio de jogos, de adivinhações, de problemas a serem inventados pelas crianças. Notamos que Alfredina destinou um amplo espaço para a retomada de conteúdos da numeração. Ao retomar conteúdos já aprendidos, esperava-se que o aluno ampliasse os conhecimentos sobre o cálculo, tendo em vista aumentar a habilidade de calcular com exatidão e velocidade a ponto de o conhecimento automatizar-se.

$\mathrm{Na}$ sequência, vinham as operações por meio das combinações fundamentais de dificuldades média, grande e muito grande, conforme resultados das experiências empreendidas por Alfredina desde $1933^{3}$. No caso da subtração, o processo de completar ${ }^{4}$ mostrou-se mais adequado para trabalhar-se na escola primária, tendo em vista a facilidade com que as crianças operavam com ele. Além disso, os resultados das testagens mostraram que, por esse processo, após intenso treinamento nas combinações fundamentais da subtração, seria mais fácil introduzir a operação de divisão.

Ao organizar o ensino a partir dos resultados de testagens, o livro de Alfredina adotou uma ordem que ia do fácil para o difícil, seguindo a ordem psicológica do desenvolvimento infantil, partindo de situações de brincadeira, que representavam a vida real, e, gradualmente, utilizando-se de saberes já aprendidos anteriormente, os alunos avançariam na aprendizagem de novos conhecimentos até a sistematização deles.

As ilustrações adotadas não eram utilizadas para exemplificar noções aritméticas, elas tinham por função contextualizar os saberes aritméticos presentes na vida cotidiana das crianças. O livro traz, por exemplo, o molde planificado de uma igreja. A partir dele, as crianças desenvolveriam a ideia dos objetos geométricos. Muitas ilustrações como as do molde foram apresentadas no decorrer do livro, em especial nos capítulos que tratavam da geometria. Apontamos que, no molde das planificações não havia medidas para confecção, apenas a orientação para que a criança reproduzisse a ilustração apresentada no livro em tamanho três ou quatro vezes maior.

A elaboração dos moldes pelas crianças requeria a utilização de algumas ferramentas do desenho geométrico (régua e esquadros) e saberes matemáticos (as noções de medida, construções geométricas, figuras planas e espaciais). Assim como os conteúdos aritméticos,

\footnotetext{
${ }^{3}$ Sobre as experiências desenvolvidas por Alfredina de Paiva Souza, ver Pinheiro (2017).

${ }^{4}$ Processo pelo qual a criança toma a quantidade menor como ponto de partida para contar até a quantidade desejada, tal como, por exemplo, na operação $7-2=5$, dois para sete faltam cinco.
} 
os geométricos eram retirados das atividades a partir de uma situação que remetia ao brincar, propondo confeccionar, com cartolinas, casas, igrejas e comércios, para que as crianças pudessem visualizar o que se desejava ensinar. Tendo confeccionado uma casa, por exemplo, a autora chamava a atenção para a aprendizagem de uma nova noção geométrica: "repare que as linhas retas das paredes se encontram sem se inclinar, nem para um lado nem para o outro. São linhas perpendiculares" (SOUZA, 1937, p. 28). Em geometria, tudo seria aprendido a partir da confecção de um material para observação associado a um conhecimento anterior.

Para além de uma análise dos conteúdos matemáticos presentes no livro didático, Bittencourt (2008) alerta-nos para a importância de considerarmos os conteúdos pedagógicos, os processos pelos quais os conteúdos deveriam ser apreendidos pelos alunos. Inferimos, pelas atividades propostas para a aprendizagem da aritmética, que o objetivo era o treinamento com vistas à habilidade e rapidez em calcular.

Os exercícios práticos das combinações eram utilizados para obter-se ou reter-se uma habilidade, entretanto, tinham o inconveniente de tornarem-se monótonos e desinteressantes para as crianças. Uma alternativa seria "fazer o exercício na forma de jogo, em competição ou por outro incentivo ou interesse que fixe a atenção" (AGUAYO, 1936, p. 246). E assim fez Alfredina, criou jogos e atividades desafiadoras para os alunos executarem os cálculos envolvendo certas combinações o mais rápido que pudessem. Após o aluno entender como se fazia o cálculo para determinar sua própria velocidade em leitura, a atividade seguinte era a execução de um teste de velocidade em aritmética, para verificar a habilidade e as dificuldades em determinada operação.

Cada teste era composto por cinquenta operações, os alunos anotavam os próprios erros, assinalando-os em uma tabela disponibilizada no livro, para verificação e controle. Os alunos eram orientados a estudar bem para, ao final de dois meses, "tornar a repetir, sem errar" as operações (SOUZA, 1937, p. 49). Percebemos que, inicialmente, o tempo seria aquele em que o aluno conseguisse realizar todo o teste. Com bastante treino, esse tempo deveria ser diminuído a ponto de os alunos poderem executar o chamado teste de diagnóstico, a ser corrigido pelo professor, pois este determinaria qual a classificação do aluno para o $4^{\circ}$ ano primário. O tempo passaria a ser preestabelecido inicialmente, e, dentro daquele período, o aluno executaria apenas aquilo que lhe fosse possível. Os testes de adição e subtração continham vinte operações em cada um, com tempo de 5 minutos, enquanto a multiplicação e divisão eram compostas por doze operações cada uma, com tempo de execução de 10 minutos. A depender do número de acertos, os alunos eram classificados como muito fraco, fraco, menos fraco, médio, pouco forte, forte e muito forte. 
No que se refere aos problemas, inicialmente as crianças inventariam os próprios problemas a partir de uma situação de brincadeira, como, por exemplo, a simulação de uma loja. O livro trazia as ilustrações dos materiais com os respectivos preços para a criança elaborar problemas simples de compra e venda. Em um segundo momento, as crianças eram treinadas a resolverem problemas similares, a retirarem informações do enunciado. Tomemos como exemplo o seguinte problema: “3 lápis custam \$600. Quanto custa uma dúzia? Procure: Preço de 1 lápis ..................... Preço de 12 lápis .....................” (SOUZA, 1937, p. 98).

A ideia geral era apresentar situações da vida real, familiares, presenciadas pelos alunos e com enunciados simples, de fácil entendimento. Todos os problemas utilizados no livro decorriam do brincar-fazendo, isto é, das brincadeiras de lojas de materiais escolares, de armazéns, da organização de festas, da compra de presentes, dentre outras. As brincadeiras próprias das crianças foram tomadas como ponto de partida para abordar conteúdos aritméticos. Nossa Aritmética não apresentava conceitos abstratos, a abstração resumia-se à representação dos números, à simbologia matemática para operar com eles. De modo geral, todos os exercícios e jogos foram elaborados de maneira a favorecer a repetição, que, à época, considerava-se “indispensável à fixação dos conhecimentos” (SOUZA, 1937, p. 183).

Ao final do livro, havia um questionário para avaliação crítica, por parte do professor, sobre as características da obra. Tratava-se de avaliar o aspecto material (qualidade do papel, tamanho das letras e algarismos, ilustrações, espaços, margens e comprimentos das linhas); as situações apresentadas (desinteressantes, convenientemente aproveitadas, aquisição de noções errôneas); a linguagem (falta de clareza, incorreções, falta de propriedade); a matéria tratada (questões deficientes, erradas, defeitos de distribuição) e outras falhas que o professor julgasse importante apontar.

O livro de Alfredina tinha características de um material autodidático para o ensino individualizado, muito utilizado nas escolas públicas estadunidenses de Winnetka ${ }^{5}$. Tratava-se de um livro em que o aluno poderia seguir sozinho na aprendizagem, reportando-se ao professor apenas para as dúvidas mais específicas, pois tinha uma linguagem que dialogava diretamente com o aluno, muitos exercícios de treinamento visando à automatização de combinações, cujo foco principal era a habilidade de calcular com rapidez e exatidão.

\footnotetext{
${ }^{5}$ Para um estudo mais detalhado do material autodidático de ensino individualizado utilizado nas escolas de Winnetka ver Pinheiro (2017).
} 


\section{Considerações finais}

Neste artigo, nos propusemos a discutir as modificações sistematizadas no livro didático de aritmética para a escola primária, considerando-se o processo de racionalização do ensino. Para tanto, analisamos Nossa Aritmética, um livro elaborado a partir de experiências científicas, em um contexto em que ideias tayloristas ganharam o espaço escolar. Falar de taylorismo escolar, a esse tempo, é falar do ensino de um mesmo conteúdo, ministrado a todos, em um mesmo lugar e ao mesmo tempo, tendo em vista melhor rendimento e eficiência. No entanto, dever-se-ia respeitar as características individuais, para que as deficiências pudessem ser superadas e o tempo otimizado. Para resolver esse paradoxo, fez-se necessária a graduação dos assuntos, advindos de experiências científicas atendendo às diferenças de ritmos de desenvolvimento, e a intenção de autodidatismo, para lidar com as diferentes capacidades dos alunos.

Tributário dessas ideias, o livro didático tomou novo rumo e passou a ser visto como um instrumento de trabalho, tanto do aluno quanto do professor. No caso do Nossa Aritmética, notamos que o público-alvo seria mais o aluno do que o professor, embora este último pudesse utilizar o livro como complemento de suas aulas, e não como ferramenta principal de sua prática. Visando atender à sua função de instrumento de trabalho, Nossa Aritmética pôs em prática atividades, exercícios e situações cotidianas que, na perspectiva da época, facilitavam a aprendizagem e a memorização de conteúdos matemáticos, tendo por base os interesses e as necessidades infantis.

No entanto, os exercícios tinham por objetivo consolidar ou verificar o resultado da ação pedagógica, mas não ser a própria ação pedagógica em si. Dito de outro modo, ainda que se tenha considerado o sujeito que aprende, seus interesses e necessidades, o que se evidencia na análise de Nossa Aritmética é a preocupação com a eficiência e com o rendimento do aluno, muito mais do que com a aprendizagem matemática. Apesar de a aprendizagem ainda não ser o foco do ensino, Nossa Aritmética inaugurou uma nova forma de elaboração de livro didático, a partir de resultados de experiências científicas.

\section{Agradecimentos}

A autora agradece o apoio da Fundação de Amparo à Pesquisa do Estado de São Paulo (FAPESP), Processo n. 2018/24382-3. 


\section{Referências}

AGUAYO, A. M. Pedagogia Científica: psicologia e direção da aprendizagem. Tradução e notas de João Baptista Damasco Pena. Companhia Editora Nacional: São Paulo, 1936. 436p.

ALMEIDA, D. H. A matemática na formação do professor primário nos Institutos de Educação de São Paulo e Rio de Janeiro (1932-1938). 2013. 103f. Dissertação (Mestrado em Educação e Saúde) - Universidade Federal de São Paulo, Guarulhos, 2013.

AZEVEDO, F. A educação e seus problemas. 3. ed. São Paulo: Edições Melhoramentos, 1953. 262p.

BINET, A. Idées modernes sur les enfants. Paris: Flammarion, 1909. 346p. Disponível em: https://gallica.bnf.fr/ark:/12148/bpt6k679262. Acesso em: 10 jan. 2016.

BUSCH, L. S. Racionalização no preparo dos livros didacticos. Idort, São Paulo, v. 6, n. 63, p. 35 61, 1937.

CALKINS, N. A. Primeiras lições de coisas: Manual de ensino elementar para uso dos paes e professores. Tradução de Rui Barbosa. Rio de Janeiro. Ministério da Educação e Saúde, 1950. v. 13. Tomo I. Obras Completas.

CHOPPIN, A. O historiador e o livro escolar. Revista História da Educação, Pelotas, v. 6, n. 11, p. 5-24, 2002. Disponível em: https://seer.ufrgs.br/asphe/article/view/30596. Acesso em: 12 mar. 2021.

CHERVEL, A. História das disciplinas escolares: reflexões sobre um campo de pesquisa. Teoria $\boldsymbol{\&}$ Educação, Porto Alegre, v. 2, p. 177 - 229, 1990.

CLAPARÈDE, E. Escola sob medida: estudos complementares sobre claparede e sua doutrina. 3. ed. Rio de Janeiro: Fundo da Cultura, 1973. 245p.

CUNHA, M. V. D. A antinomia do pensamento pedagógico o delicado equilíbrio entre indivíduo e sociedade. Revista da Faculdade de Educação, São Paulo, v. 19, n. 02, p. 189-204, jul./dez. 1993.

FAGUNDES, A. Acêrca de livros... Revista do Ensino, Belo Horizonte, v. 12, n. 149 - 151, p. 190 210, abr.jun. 1938. Disponível em:

http://www.siaapm.cultura.mg.gov.br/uploads/arquivos/revista_do_ensino_vol12_n149_151_1938.pdf . Acesso em: 26 abr. 2017.

HOFSTETTER, R.; SCHNEWUWLY, B.; FREYMOND, M. Penetrar na verdade da escola para ter elementos concretos de sua avaliação: A irresistível institucionalização do expert em educação (século XIX e XX). In: HOFSTETTER, R.; VALENTE, W. (org.). Saberes em (trans)formação: tema central da formação dos professores. São Paulo: Editora Livraria da Física, 2017. p. 55-112.

LOURENÇO FILHO, M. B. A Escola Nova (Transcrição). Educação, São Paulo, v. 7, n. 3, p. 293 301, jun. 1929.

MONT'ALEGRE, O. O livro didático. O Observador Econômico e Financeiro, Rio de Janeiro, v. 6, n. 61, p. 138-140, 1941. Disponível em: http://memoria.bn.br/hdb/periodo.aspx. Acesso em: 03 abr. 2017.

MORAIS, R. S.; VALENTE, W. R. Os Experts e o Saber Profissional do Professor que Ensina Matemática. Ciência \& Educação, Bauru, v. 26, p. 1-13, 2020. Disponível em: https://www.scielo.br/pdf/ciedu/v26/1516-7313-ciedu-26-e20029.pdf. Acesso em: 10 ago. 2020.

DEPARTAMENTO DE EDUCAÇÃo DO DistRITO FEDERAL. Programa de Matemática. 
Edição Preliminar. São Paulo: Companhia Editora Nacional, 1934. Disponível em: https://repositorio.ufsc.br/handle/123456789/115967. Acesso em: 04 mai. 2017.

PINHEIRO, N. V. L. A Aritmética sob medida: a matemática em tempos da pedagogia científica. 2017. 214f. Tese (Doutorado em Ciências) - Universidade Federal de São Paulo, Guarulhos, 2017.

PINHEIRO, N. V. L.; VALENTE, W. R. Binet e o ensino e a aprendizagem da aritmética nos primeiros anos escolares: o que ensinar, quando ensinar. Revista Atos de Pesquisa em Educação, Blumenau, v. 2, n. 2, p. 346-362, mai./ago. 2017. Disponível em: https://proxy.furb.br/ojs/index.php/atosdepesquisa/article/view/6338. Acesso em: 10 mai. 2018.

SILVEIRA, A. Novos rumos para os livros didáticos. Revista Brasileira de Pedagogia, Rio de Janeiro, ano IV, v. 7, n. 35, p. 522-523, 1937.

SOUZA, A. P. Nossa Aritmética $3^{\circ}$ Ano. Porto Alegre: Livraria do Globo, 1937. 190p. Disponível em: https://repositorio.ufsc.br/handle/123456789/136382. Acesso em: 4 nov. 2016.

VALENTE, W. R. História da educação matemática nos anos iniciais: a passagem do simples/complexo para o fácil/difícil. Cadernos de História da Educação, Uberlândia, v. 14, n.1, p. 357-367, jan./abr. 2015. Disponível em: http://www.seer.ufu.br/index.php/che/article/view/32131. Acesso em: 12 mar. 2021. 